\title{
MUSEU ESCOLAR DO COLÉGIO MARISTA ARQUIDIOCESANO DE SÃO PAULO: CONSTITUIÇÃO, HISTÓRICO E PRIMEIROS MOVIMENTOS DE SALVAGUARDA DA COLEÇÃO
}

\author{
THE MUSEUM SCHOOL OF SÃO PAULO MARIST \\ ARCHDIOCESAN COLLEGE: CONSTITUTION, HISTORY \\ AND FIRTS ACTIONS TOWARD SAFEGUARDING THE \\ COLLECTION
}

\author{
Katya Zuquim Braghini* \\ Raquel Quirino Pinãs** \\ Ricardo Tomasiello Pedro***
}

\begin{abstract}
Resumo: O artigo apresenta o Museu Escolar do Colégio Marista Arquidiocesano de São Paulo, instituição católica, confessional, fundada em 1858. O atual museu escolar do colégio guarda um patrimônio escolar científico iniciado há 150 anos e serve aos estudos voltados à história do ensino das ciências; à história das ciências e os usos de instrumentação científica; à história da divulgação científica na relação entre os locais de produção e difusão do conhecimento escolarizado. O objetivo do artigo é sondar o atual estado da coleção, mas, ao mesmo tempo, mostrar como se deu o momento inicial de sua composição, a partir do histórico de aquisição de suas peças, sempre pensado como material didático inovador e representativo da modernização do ensino das ciências. Trata-se, portanto, do estudo do "museu escolar" como biografia do espaço escolar, ou seja, entre ter sido local para o ensino de ciências e, hoje, ambiente de guarda de coleção histórica dando historicidade à noção de patrimônio como "propriedade".
\end{abstract}

\footnotetext{
* Professora no PEPG em Educação: História, Política, Sociedade da Pontifícia Universidade Católica de São Paulo. E-mail: katya.braghini@yahoo.com.br ** Mestranda no PEPG em Educação: História, Política, Sociedade da Pontifícia Universidade Católica de São Paulo. E-mail: rickpedro@hotmail.com

*** Mestrando no PEPG em Educação: História, Política, Sociedade da Pontifícia Universidade Católica de São Paulo. E-mail: rqpinas@gmail.com
} 
Palavras-chave: Museu escolar. Patrimônio escolar. Patrimônio científico. Práticas pedagógicas.

\begin{abstract}
The article presents the School Museum of São Paulo Marist Archdiocesan College, a Catholic institution, confessional, established in 1858. The current college's school museum keeps a scientific heritage which began 150 years ago and serves the studies related to the history of science education; the history of the sciences and the uses of scientific instrumentation; and the history of scientific dissemination in the relationship between the place of production and the dissemination of schooled knowledge. The aim of this article is not only to probe the current state of the collection but also to show how the composition began, starting with the acquisition records of its pieces, always thinking of it as innovative didactic material and how representative it was in the modernization of science teaching. It is, therefore, the study of the "school museum" as the biography of the school itself, i.e. having been the location for the teaching of science and nowadays the safekeeping of the historical collection, giving historicity to the notion of heritage as "property".
\end{abstract}

Keywords: School museum. School property. Scientific heritage. Pedagogical practices.

\title{
INTRODUÇÃO
}

Em 2006, é iniciado no Colégio Marista Arquidiocesano de São Paulo um projeto com o objetivo reforçar a memória institucional. Essa ação viria a ser precursora e base das comemorações dos 150 anos de existência do colégio e centenário da administração dos Irmãos Maristas em 2008. ${ }^{1}$

A constituição de um Memorial originou-se das demandas da comunidade escolar no ano comemorativo, que desejava apontar as suas próprias seleções e interesses documentais para a manutenção de suas tradições. Havia uma expectativa em torno de itens que seriam eleitos como de "importância histórica". Os resultados dessas ações - pesquisa histórica e cronologia inicial, organização prévia da documentação e o acesso ao público - foram alvos de diversas apropriações e usos pela comunidade escolar.

Tratava-se da organização de um histórico que também demarcasse a atuação do Instituto dos Irmãos Maristas como congregação sólida. Fundada em 1817, na França, pelo Padre Marcelino Champagnat, a congregação se expressa no "carisma” pela Educação, no qual o exercício da fé se apresenta por meio do ensino. As comemorações fundaram um movimento de guarda patrimonial, ao mesmo tempo em que buscava escolher, aquilo que, de maneira histórica, compusesse e acomodasse uma "forma de ser Marista" na rotina presente. Isso demonstra que, na cultura escolar em funcionamento, tenta-se 
fixar um currículo a partir de uma apropriação determinada do passado, fazendo da memória um exercício do presente.

$\mathrm{Na}$ fase de implantação do Memorial foram definidas linhas de atuação: a preservação do suporte material, sua organização e o seu acesso. Foi priorizada a identificação, organização e inventário do acervo fotográfico e de publicações produzidas pela própria escola; elaboração da cronologia e histórico da instituição; desenvolvimento de uma base de dados para registro das informações documentais que fosse acessível ao público em geral e com visualização de amostras do acervo; montagem de uma pequena exposição e contextualização dos "espaços da memória"; e a constituição de um setor responsável pela preservação e acesso ao acervo. ${ }^{2}$

No caso do Brasil, é possível perceber um esforço coletivo no sentido de preservar e organizar os arquivos escolares da parte dos pesquisadores em História da Educação, nos últimos 20 anos. Documentos guardados nesses locais são importantes para a compreensão dos processos e fenômenos sócioeducativos, para a percepção de outras formas de uso do espaço e tempos escolares e para o entendimento das ações de socialização de outras gerações de estudantes. ${ }^{3}$ Essas preocupações, mapeadas grosso modo, vão desde o estado da conservação dos documentos escolares; passam pelos diversos projetos de constituição de centros de memória e restauração de acervos, muitas vezes abandonados nos depósitos das escolas; até sobre documentos escolares digitalizados para o uso em pesquisas. Pensa-se o patrimônio material como o registro empírico de uma lógica interna que aponta para uma história de microcosmos, escolas, como universos que, ao mesmo tempo, possuem uma estrutura específica vinculada a um panorama multidimensional, consolidada nas tramas estabelecidas com outras culturas presentes da sociedade.

Historiadores da educação voltaram o seu interesse para o interior da escola, buscando compreender a "cultura escolar" como categoria de análise e campo de investigação. ${ }^{4}$ Viram-se impelidos a procurar uma documentação específica que lançasse as pesquisas para os acontecimentos cotidianos, uma etnografia da escola, pensando nos "feitos e ideias, mentes e corpos, objetos e condutas, modos de pensar, dizer e fazer" dedicando atenção para os espaços e tempos e a estruturação cultural dos sujeitos ali envolvidos. ${ }^{5}$ Aqueles que optam pelo entendimento da escola através da via da cultura escolar se deparam com duas discussões contraditórias, mas que se complementam. Por um lado, temos o problema da ausência de fonte histórica, já que as escolas, grandes produtoras de documentação e consumidoras de produtos, são também ambientes de descarte sistemático de seus registros e objetos, tão logo estes cumpram os ciclos de vida útil. Por outro lado, vemos que a ampliação do entendimento de "documento histórico" passa não só pela criatividade no momento de formulação de perguntas de pesquisa, mas pela própria compreensão, teórica e metodológica, do que vem a ser um documento que serve aos estudos históricos sobre a educação. 
A comunidade escolar do Colégio Arquidiocesano pareceu acompanhar esse movimento de guarda e manutenção de documentos que nos oriente à etnografia escolar muito embora de forma bastante particular e não diretamente preocupada com tal ação voltada à pesquisa acadêmica. Naquele momento, a constituição de um lugar de memória dentro da escola esteve estreitamente ligada às determinações de sua direção de ensino preocupada com a comemoração de seu centenário. Paralelamente, foi percebida a necessidade funcional de se criar um departamento onde fosse depositada a documentação da escola, pensando, inclusive na sua longevidade em anos, seja voltada ao passado, seja pensando na perpetuidade da "missão Marista" para tempos futuros.

O Memorial passou a responder pelos documentos considerados históricos (livros, revistas, livros de atas, cadernetas de consumo, fotografias, artefatos etc.). Esse departamento está subordinado à Biblioteca do Colégio do Arquidiocesano e ambos estão vinculados à diretoria educacional. Os objetivos gerais do Memorial são os de preservar e oferecer a documentação aos pesquisadores; fazer uso da documentação como instrumento pedagógico para atividades educativas e culturais; salvaguardar itens que estão fisicamente integrados ao cotidiano escolar.

O Museu Escolar, objeto deste artigo, é uma das coleções vinculadas ao Memorial, sendo composto por diversos objetos vinculados ao ensino das ciências (Física, Química, História Natural), levando em conta suas subdivisões disciplinares. Parte dos instrumentos são materiais escolares, concebidos para o uso didático; outros são instrumentos de precisão que foram adaptados para a ação escolarizada. Por serem materiais escolares e tecnocientíficos ao mesmo tempo correm grandes riscos de descarte sem critérios, por essas duas vias e também quando deixam de ser "inovações". ${ }^{6}$

Vemos que a maior parte da coleção científica do Arquidiocesano é constituída de modelos e de instrumentos pedagógicos, ou seja, aqueles usados com o propósito de se ensinar as ciências. No entanto, a coleção também dispõe de instrumentos de precisão, o que nos faz questionar os limites entre a ciência produzida nos locais de saber (laboratórios, centros de pesquisa, Academias) e aquilo que pode e deve ser difundido como apelo científico e histórico nas escolas. O patrimônio científico escolar passa por este duplo sentido, pois está envolto aos desígnios da inovação: novidade científica que se torna obsoleta, por vias teórica, técnica, metodológica; novidade educativa, representativa dos processos da modernização pedagógica, que acompanha os processos históricos da História das Ciências. Finalizado o ciclo de uso, acabam sendo descartados, jogados fora. São transformados em lixo. Além disso, documentos escolares acabam secundarizados, sendo, muitas vezes, considerados "menores" no campo da pesquisa histórica. ${ }^{7}$

Mesmo a questão do descarte de objetos pedagógicos é motivo de questionamento de pesquisa, pois como artefatos didáticos estão diretamente 
ligados às concepções educacionais, práticas, saberes e gestuais de um tempo, acusando as suas dimensões simbólicas, objetivas e tácitas. O rejeite destes itens é revelador das práticas que se desenvolvem e "morrem", apresentando tanto um sentimento de naturalização que se tem com a história da escola, quanto à mundanidade das ações mediante a nossa relação com os objetos. ${ }^{8}$ Enfim, a materialidade de museus escolares deve ser um exercício de salvaguarda de antigas tradições socialmente relevantes, tendo por meta pensar historicamente a Educação, discutindo-se, inclusive, a posição dos artefatos escolares, dentro dessa história cotidiana, bem como sua posição como fonte e objeto de pesquisas, já que pouco se explora essa via de conhecimento em investigações históricas. ${ }^{9}$

O Museu Escolar do Colégio Marista Arquidiocesano de São Paulo foi montado por motivos variados em que estão intercalados os seguintes eventos: a história de uma instituição católica na cidade de São Paulo em meio às discussões sobre o estabelecimento de um ensino laico e republicano na passagem do século XIX para o século XX; o apelo à modernização da educação por meio do ensino de ciências que passa a ser compreendido como uma nova expressão da humanidade civilizada e urbana; à circulação de instrumentos científicos, principalmente pedagógicos, apresentados em catálogos de vendas e que nos mostram um verdadeiro mercado de ciências que, por um lado, fomenta novos significados sobre a pesquisa científica e, ao mesmo tempo, eleva-os à posição de novos símbolos de prestígio, dando visualidade às escolas que os adquirissem.

Este Museu Escolar, ao longo de sua existência, primeiro como espaço didático, planejado e organizado para as aulas, depois, como ambiente de salvaguarda de artefatos, não deixou de receber acréscimos ao longo de sua história. Fosse por compra de novos objetos, ou por doação feita por professores e ex-alunos, hoje a coleção abriga peças de diversos períodos do século XX. Atualmente, os itens pertencentes às décadas anteriores estão expostos em armários ao lado de peças contemporâneas, resultado da última grande compra de itens de apoio pedagógico ocorrida no ano 2000.

Por uma contagem ainda imprecisa, existem 800 peças, usadas para o ensino de Física e Química, adquiridas entre a segunda metade do século XIX e o início dos anos 1980. Há instrumentos para o ensino de Mecânica, Astronomia, Hidrostática, Pneumática, Calorimetria, Ótica, Eletricidade, Magnetismo, Acústica, grande parte, adquirida antes dos anos 1930. Observando as peças que estão em exposição, percebe-se o registro dos seguintes fabricantes de casas estrangeiras: Maison Deyrolle, Les Fils d'Emilie Deyrolle, Ducretet, Machlet, Rodriguet \& Massiot, Max Kohl, Winkel Zeiss, Carl Zeiss, Welch Scientific Company, Hartmann and Brown, WM Welch Scientific Company, entre outros. Há também empresas brasileiras, tais como: Otto Bender, Franz Sturn Cia. Ltda., Techné São Paulo, Meister Irmãos etc. A coleção para o ensino 
de História Natural contém modelos anatômicos, animais taxidermizados, modelos, coleções de mineralogia, exemplares arqueológicos, etc. A maior parte dos instrumentos está em excelente estado de conservação. ${ }^{10}$

No caso deste artigo, pretende-se apresentar os diversos significados pelos quais se compreende o termo "museu escolar", demonstrando a historicidade dessa instituição dentro da escola. Depois, um histórico sobre a aquisição de objetos, ou seja, como e porque foram adquiridas as primeiras peças daquilo que hoje é uma coleção em preservação. Essa apresentação foi possível por meio da mobilização de documentos encontrados no próprio Memorial do Colégio Marista Arquidiocesano, no arquivo da Cúria Metropolitana de São Paulo e no Arquivo Nacional, localizado no Rio de Janeiro. Posteriormente, apresentaremos um relatório prospectivo de como se encontra a coleção atualmente, ainda sem inventário, nem catálogo, mas explorando os trabalhos já feitos no sentido de sua guarda e preservação. Ao final, apresentamos um relatório de sondagem do patrimônio escolar.

\section{MUSEU ESCOLAR: COLEÇÕES DE COISAS PARA O ENSINO PRIMÁRIO E SECUNDÁRIO}

Objeto com muitas definições e pouco estudado no Brasil, o Museu Escolar foi uma instituição inventada no século XIX para fins pedagógicos, surgido na era de constituição dos grandes museus no Brasil e no mundo. Como objeto de estudo e ao longo do tempo, diferentes características foram dadas à expressão "museu escolar", podendo ser, portanto, tratado como termo "polissêmico", pois ele pode ser entendido como a série de quadros parietais produzidos, por exemplo, pela Maison Deyrolle e usados para a aprendizagem de diversos conteúdos disciplinares, sendo, fundamentalmente para as "Lições de Coisas", nas escolas primárias; um móvel envidraçado onde era possível guardar os objetos utilizados para o exercício dessa mesma disciplina; local armazenador de objetos variados, recolhidos pelo professor e/ou pelos alunos; gabinetes que ocupavam um espaço físico, dentro de laboratórios ou salas, usado para a guarda de coleções. ${ }^{11}$

Percebe-se que ao longo do século XIX, o ensino dito "livresco", amparado na memorização de saberes, teve críticas ora dispersas, ora pontuais, mas que, ao final do século, foram se avolumando, de modo tal que, nesse período, se tornou homogêneo e teve alcance mundial. Houve a ampliação de um tipo de ensino que fosse amparado pelo saber constituído por meio da experiência, fazendo com que os alunos tivessem contato com a "realidade", de modo a não serem levados, apenas, pelo conteúdo de livros e pela apreensão de conhecimentos de forma mnemônica. Tal proposta pedagógica, cujo aprendizado se dava por meio do contato direto com os objetos, se alastrou 
mundo afora sob a designação de "método intuitivo". Isso significava fazer do professor um sujeito atuante no sentido de organizar atividades que gerassem graus sucessivos de complexidade, permitindo ao aluno o conhecimento pautado, passando das noções concretas às abstratas.

No caso do ensino secundário, a constituição do que à época ficou conhecido como "humanidades científicas" estava amparada na contraposição ao modelo destinado fundamentalmente à formação em torno das Humanidades clássicas, cujo eixo central era a retórica. ${ }^{12}$ Para possibilitar o desenvolvimento desse novo espírito científico, produziu-se grande variedade de materiais escolares e didáticos, desde o mobiliário até objetos de uso pessoal do estudante (caderno, lápis, livro didático, etc.). ${ }^{13}$ Dentre a grande variedade de objetos que entraram na escola, encontrava-se "para o ensino de ciências físicas e naturais: laboratórios, museus, quadros Deyrolle, estampas, quadros de história natural, esqueleto humano, bússola, microscópio, peças anatômicas, mapas de física". ${ }^{14}$

Para acomodar tantos materiais, o próprio edifício escolar passou por definições e regulamentações arquitetônicas, com previsão de espaços especialmente projetados para essas atividades. Estabeleceram-se novas metodologias e práticas de ensino. No caso dos estudos científicos, foi necessário pensar em ambientes especiais para abrigar laboratórios e seus instrumentos, museus pedagógicos com acervos de zoologia, anatomia, botânica, mineralogia, etc.

A reforma educacional Leôncio de Carvalho (1879) é apresentada como a primeira menção, acontecida no Brasil, sobre a necessidade de implantação de museus escolares com finalidade didáticas para o ensino de ciências. Essa prescrição estabelecia a criação de espaços pedagógicos diferenciados para a execução de atividades didáticas e, dentre eles, faz menção à criação de museus escolares. ${ }^{15}$ Os museus escolares acompanham o processo histórico de construção de grandes museus, de ciências, história ou de arte. Entretanto, está ligado também à organização de museus pedagógicos de grande porte, que foram instituições criadas para que fossem apresentadas ao público escolar professores, diretores de escolares e administradores da instrução pública - os mais modernos materiais de ensino, visando apresentá-los como objetos de consumo e elementos representativos da modernidade pedagógica. ${ }^{16}$

No caso do Brasil, destaca-se a criação do Pedagogium, museu nacional do tipo educacional e comercial, que foi criado especialmente para fins de apresentação de objetos pedagógicos. Pedagogium foi o termo dado ao Museu Escolar do Distrito Federal por intermédio do Decreto $n^{\circ}$ 980/1890, localizado no Rio de Janeiro, que tinha dentre as suas funções organizar exposições permanentes, conferências e cursos científicos adequados ao fim da instrução pública da época e à exposição de gabinetes de laboratórios para o estudo prático das "sciencias physicas e história natural". ${ }^{17}$

Diante da possibilidade de "catalogação do mundo", percebe-se que, mesmo as propostas de ampliação de conhecimento dadas pelos museus 
científicos, tinham o interesse de maior intercâmbio com o que se passava nas escolas. Esse relacionamento foi demarcado pela cessão de kits didáticos enviados pelos museus para as escolas. Museus não só recebiam os alunos, mas também emprestavam as coleções para o uso dos professores. ${ }^{18}$ Neste sentido, vemos um movimento de escolarização de museus pensado como exercício das representações do método intuitivo, para além dos muros da escola. Entre as escolas e os museus houve uma "reflexão comum" sobre o uso do objeto na "aprendizagem e de sua importância na 'lição de coisas"”. O Museu do Ipiranga foi constituído dentro de um plano de educação paulista interessado no relacionamento entre a instituição e as escolas públicas beneficiando o exercício didático com essa disciplina escolar. ${ }^{19}$ Aliás, a ideia de observação da natureza, por meio dos sentidos - base do método intuitivo e fundamento das Lições de Coisas - está entre as razões de criação deste museu. Esse intercâmbio aconteceu também entre o Museu Nacional e o Colégio D. Pedro II. ${ }^{20}$

Devemos considerar que, em meio às preocupações de caráter pedagógico, há ainda o caráter comercial, já que tratamos de objetos que deviam ser adquiridos pelas escolas e pelas administrações governamentais das províncias, apresentando, ao mesmo tempo, tanto o caráter de novidade, quanto de efemeridade, já no momento de sua aquisição. Trata-se de perceber que as circulações desses objetos, apresentados em exposições escolares, também eram vistos em museus comerciais, Exposições Universais e catálogos de vendas variados, classificando-os por uso, funções, design, fabricantes etc.

À época, tamanha era a relação entre Exposições e Museus que não soava estranho o emaranhamento do léxico entre eles, quando o assunto era o aspecto da apresentação visual de peças nos diferentes espaços. "O que é a exposição? É museu ou uma feira? A exposição do centenário era um museu". ${ }^{21}$ O comentário apresentado no relatório da exposição de Paris é próximo ao que foi registrado pelo autor do Catálogo da Biblioteca do Museu Escolar Nacional a respeito da Exposição Pedagógica no Brasil, quando disse: "o terceiro salão desse Museu despertava a atenção do visitante", porque, dentre os vários objetos expostos estavam "apparelhos para o estudo da physica, da chimica", "systema metrico e para o ensino intuitivo", "arithmometros de varios autores, mineraes", etc. ${ }^{22}$

Os museus escolares foram tornados preceitos importantes para o ensino das ciências e fazem parte de uma série de dispositivos, educacionais, comerciais, científicos, artísticos, que, em meio às preocupações da educação dos sentidos, demonstram a priorização dada à forma museal de visualização de objetos. Isso não significa pouco, pois se tratava de entender, ou sentir, a visualidade como uma via de formação generalizada, o que qualificou os objetos como itens imprescindíveis de consumo e educação escolarizada. Mas, deve-se levar em conta que o apelo à visualidade era próprio do tempo e não era uma especificidade dada pelo modelo pedagógico da época. Ver coisas expostas e ter 
à mão objetos era um apelo do comércio, pela exposição das vitrines, condição da publicidade exposta em jornais e revistas em circulação e aos reclames de produtos que passam a ser parte da rotina nas cidades.

Em contrapartida, percebemos o desvanecimento histórico do sentido do tato, da inferiorização da manipulação como prática escolar, do apelo dado às mãos que é inseparável da própria condição de existência do objeto.

\section{MUSEU ESCOLAR DO COLÉGIO MARISTA ARQUIDIOCESANO DE SÃO PAULO: AQUISIÇÃO DO MATERIAL DIDÁTICO E PRÁTICAS ESCOLARES}

O mundo dos artefatos materiais invadiu o sistema público de ensino no Brasil seduzido pelo fascínio de uma pedagogia dos sentidos. A entrada de objetos pedagógicos para a educação escolarizada no século XIX, conta muito sobre os projetos modernizadores voltados à Educação. A instalação do gabinete de ciências do Arquidiocesano não deve ser compreendida de maneira isolada, mas incluída no movimento social que investia na aquisição de toda sorte de materiais para ativar um modelo educacional específico.

Portanto, pensando no universo educacional, não se trata de perceber os instrumentos científicos nessa escola como valores em si mesmos, mas como desejos utilitários envoltos em um procedimento pedagógico que dava importância aos objetos em geral e reservava aos instrumentos científicos uma estima especial, dada a sua representatividade no mundo moderno. Instrumentos científicos podem ressaltar teorias; eles mesmos podem ser uma teoria, marcados no mundo como a forma de um pensamento. Eles foram usados para o entretenimento de plateias em diversas cidades do mundo, circulavam em circos e em apresentações agendadas em teatros; eram fundamentais à divulgação científica para um público amplo composto, também, pela comunidade escolar.

Tratamos aqui de ressaltar os primeiros movimentos de aquisição desses objetos que foram a base do museu escolar do colégio em pauta, jogando o seu histórico para a segunda metade do século XIX. 
Figura 1 - Gabinete de Physica e Museu do Collegio Diocesano, sede do bairro da Luz, 1906

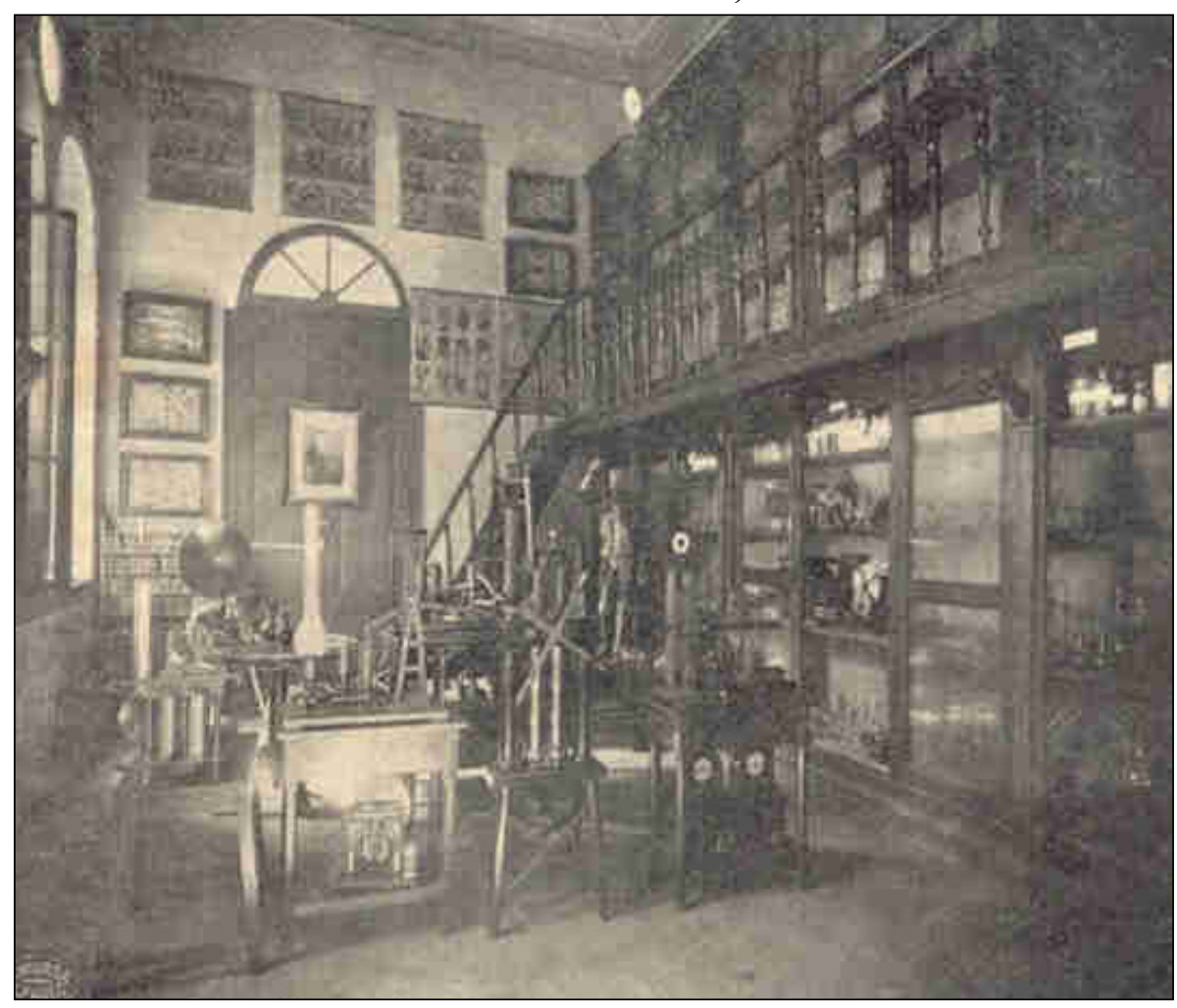

Fonte: Memorial do Colégio Marista Arquidiocesano de São Paulo

Frei Germano d'Annecy, capuchinho, batizado Claude Charles Marion, foi o primeiro responsável pela montagem de um gabinete de ciências no colégio. Nascido na cidade francesa de Annecy, chegou a São Paulo em 1858 para ser professor de Física, Matemática, Astronomia, Botânica e Mineralogia, do então Seminário Episcopal de São Paulo (1856), desmembrado dois anos mais tarde em colégio confessional, católico, sob regime de internato, masculino: Seminário Diocesano, Maior, para a formação de clérigos, e Menor para a educação de jovens moços. ${ }^{23}$ Frei Germano ganhou proeminência no país, por conta de seus estudos astronômicos feitos em um telescópio instalado no terraço do Seminário. Também em um dos pátios do colégio havia um gnômon ${ }^{24}$ mural vertical declinante que marcou a hora oficial da cidade. Ficou conhecido como astrônomo renomado, tendo recebido convite de D. Pedro II para ser vice-diretor do Imperial Observatório, no Rio de Janeiro. Fez diversas experiências em iluminação elétrica ao ar livre em São Paulo, Campinas, Franca e Uberaba. ${ }^{25}$

O religioso permaneceu como professor de Ciências do Seminário até 1878, quando se deu a retirada, pouco pacífica, dos capuchinhos da direção da instituição que passou à Diocese. Mesmo afastado do cargo de professor, 
mas ainda residente na cidade de São Paulo, o religioso esteve disposto a trabalhar em benefício do seu antigo gabinete de física: "propunha a venda de seus instrumentos de física e química por dois contos de réis, ficando ele na organização de vir montar o gabinete do Seminário". ${ }^{26}$

O posterior diretor do gabinete de física, Padre João Batista Vanesse, indicado pela Diocese, listou instrumentos científicos e outros objetos que foram, mais tarde, recebidos pelos Irmãos Maristas, no requerimento para o pedido de equiparação do colégio ao Ginásio Nacional, apresentado em julho de $1900 .{ }^{27}$ Segundo o registro, o colégio tinha um "jardim interior com a estátua do bispo fundador e com o relógio de sol, além dos gabinetes de física, química e história natural". ${ }^{28}$ De acordo com o documento, o Museu Escolar, gabinete de Física e laboratório de Química se apresentavam como ambientes diferenciados organizados em um mesmo espaço.

O museu escolar foi apresentado pela apreciação dos itens contidos nos armários que, segundo consta, guardava uma "bela coleção de mármores"; "grande coleção de pedras"; "importante coleção de conchas"; "coleção regular de aves, quadrúpedes, anfíbios, peixes e cobras embalsamadas e em vidros de álcool"; "riquíssima coleção de moedas antigas" e "completa coleção de moedas novas". Portanto, se tratava de um espaço especificamente voltado para o ensino de História Natural.

Já os gabinetes de Física e Química possuíam 61 instrumentos acompanhando ao que era estabelecido como currículo obrigatório apresentado no então colégio secundário de referência nacional, o Colégio D. Pedro II (à época denominado Ginásio Nacional). ${ }^{29}$ Percebe-se pela fotografia (Figura 1) que o Gabinete de Física e o Museu Escolar do Colégio Arquidiocesano estavam bem montados e contavam com vidrarias diversas, elementos químicos, bombas pneumáticas, bomba de vácuo, máquina de Winchester, máquina de Whimshurst, fonte de Heron, quadros parietais e o modelo anatômico humano da Maison Deyrolle.

Esse primeiro espaço de ciência do colégio foi montado de forma tal a atender às especificações dadas pelo currículo, mas, ao mesmo tempo, apresentou-se como espaço organizado a partir das determinações específicas dadas pelo professor como o principal motivador do currículo. No caso, frei Germano, que agremiava a função de ministrar aulas de várias disciplinas científicas e seus respectivos subitens, organizou um único espaço de ciências em que os vários objetos estavam à disposição do olhar, apresentando as representações de ciência que valiam a guarda, ordenada e classificada, e o estudo. Além disso, esses objetos ficavam à mão do professor de modo que pudessem ser apresentados no próprio gabinete ou levados às salas de aula para as atividades.

A coleção de instrumentos científicos foi sendo ampliada paulatinamente entre os primeiros anos do século XX até a década de 1940. O aumento 
gradativo da coleção acompanhou as alterações das estruturas das disciplinas científicas, seus conteúdos e focos privilegiados, e mesmo a constituição de novas disciplinas voltadas ao ensino das ciências. ${ }^{30}$ Nesse mesmo período, houve o deslocamento da sede do colégio do bairro da Luz para o da Vila Mariana. A partir da construção de um novo prédio, totalmente modelado pelas normas prescritivas federais de planejamento escolar, foram arquitetados novos espaços para as aulas de ciência e, consequentemente, houve a ampliação dos ambientes possíveis para a guarda de novos objetos. ${ }^{31}$ No Livro de Occorrencias Diarias, de 1935, percebem-se claramente as novas aquisições de materiais: "A installacção nova do Collegio no amplo e sumptoso edifício actual trouxe como consequência a ampliação de todo o material nas vastas salas de Physica, Chimica, História Natural e outras, o que vem sendo feito de maneira a, em breve, ser um dos melhores estabelecimentos congêneres". ${ }^{32}$

Além disso, há a percepção de que outras instituições de ensino, públicas e privadas, também passaram a comprar esses instrumentos, primeiro buscando acompanhar uma progressiva alteração do currículo escolar do ensino secundário, que no final do século XIX, passou a valorizar os conhecimentos tecnocientíficos. Diante do público, museus escolares passaram a ser vistos como chamarizes para o público, apresentados em chamadas publicitárias de escolas em jornais, como forma de chamar a atenção para o ensino das escolas que se apresentavam como concorrentes. ${ }^{33}$

No caso do Colégio Marista Arquidiocesano, os materiais de ensino e, particularmente, os instrumentos científicos, fizeram parte dos planos de expansão da instituição, disposta a se apresentar na cidade como um colégio voltado à formação de uma comunidade masculina com origens sociais heterogêneas. Um dos resultados desse movimento foi o estabelecimento de um critério de formação afastado de suas origens francesas, de educação voltada aos humildes. Como objetos representativos da modernidade científica e pedagógica, os instrumentos científicos, base de gabinetes de ciências e do museu escolar, eram apresentados como elementos distintivos que concediam prestígio à instituição, pela apresentação de seu mostruário, que ao mesmo tempo era conteúdo e recurso pedagógicos. Por outro lado, ao seguir os padrões estipulados pelo Colégio Pedro II, havendo interesse na "equiparação", o colégio buscava seguir ordenação jurídica laica, se estabelecendo dentro dos limites da jurisprudência, de modo a fazer frente à instituição de grupos escolares e ginásios públicos que, no mesmo período, se apresentavam como verdadeiros palácios de boa educação civilizada e republicana.

Ações de valorização do patrimônio, identificação e preservação, primeiros movimentos

Não é raro encontrar profissionais responsáveis por acervos históricos escolares que relatam cenários caóticos sobre como encontraram as coleções nas quais trabalham. Mesmo o Museu Escolar do Arquidiocesano passou por 
períodos obscuros e a sua coleção já sofreu ameaça de descarte, tratada como aglomerado de objetos didáticos obsoletos, ligados às pedagogias antigas. No abandono, peças antigas, perdem totalmente o seu significado. Já em museus, os objetos apresentam-se com a perda de suas funções originais e são transformados em documentos históricos, que podem ser decifrados como produtos e vetores da ação humana.

A coleção do colégio passou por uma fase de abandono, entre o final dos anos 1950 e meados dos 1960 e especialmente os instrumentos para ensino de Física e Química sofreram o desgaste natural do tempo, agravado com o acondicionamento inadequado.

As condições ambientais inadequadas são apontadas como a causa mais séria de deteriorização das peças. Especialistas na conservação e restauro de instrumentos científicos advertem que alguns efeitos permanecem imperceptíveis por muito tempo, mas, que ao serem percebidos, já podem ter danificado a estrutura do objeto. ${ }^{34}$

Por meio dos relatos de professores, hoje aposentados, descobriu-se que o espaço de guarda dos instrumentos constituiu-se em um depósito caótico de coisas: lentes perdidas, lâmpadas quebradas, peças soltas, vidros rachados, peças de bronze oxidadas, cobertas com zinabre, infestadas por cupins, correias de couro partidas etc. A solução para tais problemas seria o descarte de peças ou a guarda de partes da coleção.

Como afirmamos, houve a sugestão de eliminação do acervo. Esse episódio coincide com a chegada ao colégio do Professor Luiz Hermínio Marcarini que lecionou, entre os anos de 1967 a 1999, a disciplina de Física, sendo durante todo esse período responsável pelo laboratório da disciplina. Foi este professor que reconheceu nas peças a relevância como raridade documental (ele também entendia como recurso didático válido, devido ao fato de ter sido formado por meio desses objetos), e que iniciaria, na década de 1970, o trabalho gradativo de reestruturação do Museu Escolar, em conjunto com alunos do curso colegial em Ciências Exatas.

Nos anos 1980, por conta da ausência de espaço para acondicionar uma quantidade numerosa de aparelhos antigos, foi idealizada uma disposição de armários que ainda se mantém como a atual possibilidade de guarda de tais objetos.

No laboratório de Biologia são mantidos, em armários dispostos na sala e em um mezanino, os antigos modelos de Botânica, Zoologia e Fisiologia usados nas aulas de História Natural, bem como a coleção de rochas para as aulas de Mineralogia. É possível constatar, pelo estado de conservação, que a coleção de História Natural está em melhores condições, muito embora seja possível averiguar a passagem de camadas de verniz, de forma inadequada, em parte dos modelos voltados ao ensino de Zoologia e Fisiologia Humana. 
Já o exame técnico panorâmico das peças para o ensino de Física e Química nos mostra que, ao longo das décadas de 1960 e 1970, parte dos objetos sofreram interferências e "consertos" incorretos dentro dos padrões da atual política de salvaguarda de instrumentos tecnocientíficos. Foram utilizando pregos, parafusos e colas, além da aplicação de vernizes que tinham por intenção dar aparência de "arrumado", e que de forma alguma tinham a intenção de restauro. Até o ano de 2008, muitas das informações relativas aos instrumentos para o ensino de Física - uma das coleções que compõe o Museu Escolar - havia se perdido. As peças também estavam aglomeradas nos armários, sem identificação e mantidas fechadas, apenas recebendo cuidados básicos de higienização. Atualmente, os instrumentos científicos estão dispostos em armários distribuídos nos átrios (do $1^{\circ}, 2^{\circ}$ e $3^{\circ}$ andares) e pelos corredores do $3^{\circ}$ andar do edifício.

Com as comemorações de centenário e sesquicentenário em 2008, houve um impulso nas ações de preservação dos acervos históricos institucionais, por isso algumas atividades puderam ser realizadas junto ao Museu Escolar. A partir dos trabalhos de recuperação das informações sobre esse acervo, foram montadas ações de valorização de seu patrimônio e divulgação de sua existência junto à comunidade escolar. A elaboração de painéis informativos sobre o Museu Escolar foi uma das primeiras atividades de modo a deixar visualmente claro o longo período de atuação do colégio na formação de jovens e a tradição do seu ensino voltado às ciências. No período da comemoração, foram realizadas palestras, dinâmicas de sensibilização sobre o significado da memória histórica e o estabelecimento de contato com pesquisadores acadêmicos que se mostravam sensíveis aos movimentos de salvaguarda de todo acervo do Memorial na sua fase de constituição.

No caso dos instrumentos, a primeira ação foi a elaboração de uma lista dos instrumentos referentes ao ensino de Física. No contato com a coleção, a equipe do Memorial percebeu que a identificação dos aparelhos científicos não seria possível sem o auxilio de um profissional da área científica com vivência educacional. Os trabalhos de identificação das peças e a descrição básica sobre a utilização do aparelho foram realizados também pelo professor Marcarini, em conjunto com a técnica documentalista a profa. Raquel Quirino Piñas. Para a apresentação desta primeira listagem básica, que não segue ainda os padrões museológicos de inventariação, foi feita a consulta em catálogos de vendas de empresas especializadas que comercializavam as peças, e edições antigas de livros didáticos de Física da Editora F.T.D., elaborados por Irmãos Maristas, também presentes no acervo do Memorial. Foram identificadas 685 peças pertencentes aos diferentes ramos de estudos da Física. Percebe-se que essa listagem não compreende, ainda, nem toda a coleção do Museu, já que não foram incluídas as peças para o ensino de Química e História Natural. Exemplo disso diz respeito à coleção de mineralogia, formada por mais de 
mil exemplares de rochas, sem identificação, escondidos em armários nos mezaninos dos laboratórios.

No entanto, foram a partir destas primeiras iniciativas que a comunidade escolar passou a ter uma postura de zelo e valorização em relação aos itens do Museu Escolar, e foi possível conseguir, paulatinamente, recursos para algumas melhorias na guarda da coleção. Para a identificação dos itens, foi iniciado um trabalho de registro fotográfico das peças por amostragem, que se limitou a captação de imagens para a sua divulgação. Foram adquiridos 47 novos armários para a guarda dos objetos que continuam expostos nos corredores e átrios de três pisos do edifício escolar. Os armários destinados aos aparelhos para o ensino de Física foram revestidos de insulfilm, padrão museu, com o intuito de minimizar efeitos da fotodegradação, fato que ainda não aconteceu com o mobiliário destinado aos animais taxidermizados.

Nas coleções antigamente voltadas ao ensino de História Natural, foi realizada a avaliação dos modelos anatômicos e feito o encaminhamento para o restauro de 15 peças. Importante ressaltar que as intervenções emergenciais para a preservação, mesmo que com limitações técnica e orçamentária, foram realizadas de forma criteriosa e satisfatória.

No final do ano de 2009, com a venda do centenário Colégio Marista de Santos para o Município, foi realizada a transferência de seus acervos. Os objetos que constituíram um dia o Museu Escolar, e se encontravam abandonados há décadas, foram entregues ao Memorial do Colégio Marista Arquidiocesano, que realizou os primeiros trabalhos de higienização, transporte e listagem de identificação básica das peças. Essa coleção remanescente de outra instituição de propriedade dos Irmãos Maristas é constituída por 142 itens, essencialmente instrumentos para o ensino de Física, apresentando um avançado estado de deterioração, causados pela ação dos fatores climáticos decorrentes do fenômeno da maresia (ferrugem, corrosão, etc.) e infestação de cupins em suas bases de madeira. Encontram-se guardados nos mezaninos dos laboratórios de Física e Biologia, visto que a instituição não dispõe de espaço adequado para a organização de tamanha coleção e, até então, não cedeu recursos financeiros, nem para o tratamento e restauro dessas peças, nem para a ampliação dos espaços de guarda.

\section{PROSPECÇÃO DOS PROBLEMAS E FUTUROS DESAFIOS}

Longe de ter alcançado um modelo de tratamento de acervo, todas as ações do Memorial perante o Museu Escolar visaram à proteção emergencial das coleções do risco de deterioração. O Colégio mantém uma estrutura apropriada para a consulta e pesquisa de seu material. As intervenções concentraram-se na higienização e identificação, não tendo sido possível, inclusive por falta 
de mão de obra, elaborar e aplicar uma política adequada de preservação. A ausência de pessoal especializado e em quantidade suficiente - atualmente possui uma profissional para os trabalhos desenvolvidos junto a todos os acervos sob guarda ou supervisão do Memorial - limita os trabalhos junto ao Museu Escolar nas seguintes atividades: a) atendimento às solicitações dos pesquisadores acadêmicos, garantindo o acesso às coleções; b) treinamento e acompanhamento das equipes de limpeza responsáveis pelas peças; c) revisão frequente das peças, dos armários, etiquetas e placas de identificação; d) avaliação e encaminhamento para restauro das peças em estado crítico de deteriorização.

As limitações de espaço são um problema para toda a coleção do Museu Escolar. Não existem espaços distintos para a guarda ou exposição do acervo. Os armários no qual as peças estão colocadas cumprem precariamente as duas funções. $\mathrm{O}$ mobiliário não foi confeccionado para a guarda desse gênero de acervo, falta vedação que impeça a entrada de poeira, pequenos insetos e até lixo. As portas apresentam problemas com travas e dobradiças, algumas não são abertas pelo risco de quebrarem. A ausência de prateleiras ajustáveis força a guarda das peças por tamanhos, desmontadas e até mesmo encaixotadas.

Os itens apresentam-se de forma entulhada, dentro dos armários, sem a possibilidade de organizá-los e muito menos acondicioná-los de forma apropriada. A posição dos armários nos corredores que levam às salas de aulas e aos laboratórios limitam os horários e períodos nos quais o acervo pode ser manuseado por técnicos e pesquisadores. Além disso, os armários, por estarem dispostos nesses espaços provisórios, estão sujeitos à umidade em dias frios, calor excessivo, iluminação direta, o que, em todos os casos, acelera a deteriorização das peças. $\mathrm{O}$ caso mais crítico diz respeito à manutenção dos animais taxidermizados, que são bastante sensíveis às condições climáticas, o que pode ativar a deformação das peças, decomposição da matéria orgânica, desbotamento das cores dos animais, etc. Além disso, existem peças "escondidas" em caixas e nos mezaninos dos laboratórios, por falta de espaço e acondicionamento adequado, que necessitam de intervenções específicas de conservação e restauro, sem expectativa de orçamento para isso.

Em outras palavras, do ponto de vista museológico falta ainda a composição de um plano diretor, um regimento, a organização da documentação relativa à coleção (aquisição - compra doação, permuta -, arrolamento, inventário, registro fotográfico, classificação, catalogação e pesquisa). No sentido da conservação, pretende-se manter uma reserva técnica, com qualidade de ar, temperatura e iluminação adequadas à coleção que, por sua natureza (instrumentos técnicos científicos, de metal ou madeira, e animais taxidermizados), depende de conhecimentos especializados para a sua preservação (limpeza, desmontagem, restauração), cuja prática é ainda recente no Brasil e no exterior. ${ }^{35}$ Falta um tratamento adequado, dentro das especificações museológicas específicas às tipologias das coleções. 
Outros três grandes desafios em torno da política de salvaguarda de documentos dentro do Colégio Marista Arquidiocesano dizem respeito às políticas de gerenciamento arquivístico de documentos, o que envolve a coleção de instrumentos científicos, que aqui são escolares, em um problema de ordem museológica. Sendo material didático escolar, os instrumentos históricos, dentro da política da escola, ainda são usados para finalidades educacionais. A questão que circunda esse fenômeno escolar é a seguinte: levando em consideração que a peça guarda marcas de historicidade de seu uso ao longo do tempo, é justo que essa coleção ainda seja usada como material didático? Essa é uma polêmica que está no cerne da posição dos instrumentos científicos históricos guardados em instituições escolares.

Por fim, ainda há a questão da conscientização contínua da comunidade escolar, principalmente docente e discente. As peças do Museu Escolar ainda são utilizadas em aulas principalmente de Ciências, Biologia, Física, Química e Robótica. Isso parece demonstrar que os docentes reconhecem esses instrumentos antigos como recursos didáticos, muito mais como recurso pedagógico do que como documento histórico. O fato de a coleção estar integrada ao espaço de circulação e às práticas escolares fez com que ele fosse muito mais percebido a partir de sua função utilitária, evidenciando o fato de que a preservação nem sempre foi uma preocupação constante. Essa é uma questão que ainda merece amplo debate, pois na museologia pede-se o congelamento das práticas sobre o objeto, de modo que fiquem fixadas as marcas e a historicidade da peça. Mas, esse pedido de solidificação do uso de peças em coleções escolares vale da mesma forma? Talvez essa seja uma discussão em torno mesmo do conceito de cultura material escolar: afinal, a coleção de instrumentos do colégio é, nos dias de hoje, recurso pedagógico ou documentação histórica?

\section{CONSIDERAÇÕES FINAIS}

No campo dos estudos sobre instrumentos científicos históricos, a coleção do Colégio Marista desponta como uma das mais significativas no país, principalmente por conta da quantidade de material disponível para a consulta. Essa coleção possui peças adquiridas desde a segunda metade do século XIX até o final da década de 1980, o que significa ter a disposição do público pesquisador, seja ele acadêmico ou não, a história da ciência, do ensino de ciência e da divulgação científica acontecida em 150 anos. Pouco se sabe sobre o consumo, uso e posterior manutenção dos instrumentos científicos voltados à educação escolarizada. ${ }^{36}$ No entanto, pensando o museu escolar como um patrimônio, que na forma de propriedade, deve ser historicizado, percebe-se que a sua coleção foi usada para dar cabo a diversos objetivos e finalidades. 
Em um primeiro momento, a coleção apontava para uma apropriação concreta dos objetos da modernidade como forma de relação entre o colégio e o público em fase de escolarização. Tratava-se, também, de se pronunciar diante da organização Estatal, laica e republicana, que no caso de São Paulo, apontava para a criação de um sistema de ensino gradual, seriado, que administraria de forma pública, pouco democrática, crianças e jovens, desde o jardim da infância até as portas da universidade. O colecionismo científico estava ligado ao prestígio que tais peças proporcionavam às escolas que delas fizessem uso $\mathrm{e}$ a intenção do colégio foi de se anunciar pedagogicamente inovador, diante do mercado estimulador, da concorrência entre escolas, e do próprio entendimento que a escola, sendo católica, tinha de Ciência.

Nos dias atuais, após um período de abandono, o Museu Escolar do Memorial do Colégio Marista Arquidiocesano de São Paulo pode ser caracterizado como museu de ciência e tecnologia, além de coleção escolar, dada à característica de sua coleção. O patrimônio da ciência e da tecnologia na "esmagadora maioria dos países é desconhecida" e esse tipo de coleção é "matéria negra" ${ }^{37}$ no universo do patrimônio. ${ }^{38}$ Esse tipo de coleção associada à difusão e ao ensino do conhecimento científico no ambiente escolar é em geral ignorado, quer no sentido dos usos escolares dessas peças, quer no sentido de manutenção de um patrimônio científico escolar. O motivo para a aquisição dos aparelhos científicos pelas escolas, durante o século XIX, é um ponto obscuro nos estudos voltados à história das ciências e das técnicas. Do mesmo modo, do ponto de vista dos historiadores da educação, pouco se sabe sobre os usos didáticos desses aparelhos em sala ou a relação entre esses materiais e os conteúdos das disciplinas escolares voltadas às ciências.

A peça depositada em museu carrega consigo informações sobre o passado e permite construir significados, a partir do que é possível dentro do espaço museológico. Os museus guardam e expõem suportes variados, tanto para a exposição quanto para disseminar conhecimentos. Os objetos, ao serem transportados de seu contexto primário para o espaço do museu, não necessariamente levam consigo informações sobre a sua função, o seu uso. Sua materialidade não serve como exata referência do passado, nem apresenta de pronto toda a carga simbólica que um dia esteve associada ao seu uso e ainda corre-se o risco de se criar uma pesquisa fetichizada. Não se trata apenas de focá-los pensando no seu consumo alienado. Trata-se de perceber a coleção como uma coletânea de formas rituais, gestuais, que do passado foram materializadas em objetos. Estão demarcadas as significações singularizadas de seus consumidores, pois os objetos servem à ação e podemos percebê-los levando em conta os contextos históricos em que esse contato aconteceu.

Ao final, como coleção escolar, trazem consigo um problema de ordem teórica que aponta para a imprecisão conceitual do termo "cultura material escolar". ${ }^{38}$ Se tratamos o objeto como o elemento material que aponta para 
relações sociais, deve-se levar em conta que muitos artefatos foram concebidos para o uso dentro de escolas, mas ultrapassaram essas fronteiras, disseminados como objetos de uso generalizado, tais como lousas e carteiras; do mesmo modo, outros tantos objetos ganharam outras significações ou foram apropriados pelo universo escolar de modo a transformá-lo em saberes escolarizados.

Como patrimônio científico, esses artefatos nos fazem pensar nas carreiras curriculares e nas diversas formas de apropriações e usos dos sujeitos que ensinavam ciências; os mecanismos educacionais utilizados para a divulgação dessas disciplinas; a história dos métodos científicos na relação entre o saber escolarizado e o saber especializado e nas diversas capacitações (ou não) dos docentes para o trato didático com tais utensílios; as políticas educacionais propostas para a introdução de inovações tecnológicas, bem como, os processos de abandono de tais novidades em benefício das subsequentes descobertas científicas; os seus atributos físicos como vestígios da estética, do design, do processamento das técnicas de fabricação, produção, circulação e venda, etc. Apresentam que a visualidade tem convenções próprias dadas no tempo; congelam técnicas, métodos e teorias em sua materialidade.

Trata-se, também, de pesquisá-los simplesmente porque são interessantes, geram curiosidades e produzem no pesquisador uma inquietação imediata: por que e como esses objetos eram usados em sala de aula? Essa é a motivação essencial: ter curiosidade com as mudanças dos processos históricos escolares de modo a mantê-los salvaguardados como admiráveis contadores de histórias de outras gerações escolarizadas.

\section{NOTAS}

1 Fundado em 1858, em anexo ao Seminário Episcopal, o então chamado Colégio Diocesano, funcionou em suas cinco primeiras décadas sobre gestão dos Freis Capuchinhos de Sabóia e dos padres diocesanos. Em 1908, a partir de um pedido do então arcebispo Dom Duarte Leopoldo e Silva, a instituição passou a ser administrada pelo Instituto dos Irmãos Maristas, congregação francesa, dedicada à educação, fundada pelo Padre Marcelino Champagnat. O Colégio passou a ser chamado Arquidiocesano, denominação mantida até hoje, em virtude da elevação da diocese de São Paulo para arquidiocese também no ano de 1908.

2 Para maiores informações sobre o Memorial do Colégio Marista Arquidiocesano, visite o site: <http://200.231.66.1:8080/griffo/site/index.php>.

3 MOGARRO, Maria João. Arquivos e Educação. A construção da memória educativa. Revista Brasileira de História da Educação, Campinas, n. 1, p. 75-110, 2001.

${ }^{4}$ Como exemplo, apresentamos a constituição e organização de arquivos escolares no estado de São Paulo: O Centro de Memória da Educação da Faculdade de Educação da Universidade de São Paulo (CME-FEUSP) que está sob a coordenação da Profa. Dra. Carmen Sylvia Vidigal Moraes. Disponível em: <http://www.cme.fe.usp.br/>. O Centro de Memória e Acervos Históricos do Centro de referência em Educação "Mário Covas" (CEMAH-CRE) que tem como objetivo implementar uma política de preservação da memória e do patrimônio histórico- 
cultural das escolas públicas estaduais paulistas. Disponível em: $<$ http://www.crmariocovas. sp.gov.br/memorial.php>. O Centro de Memória da Educação da Unicamp (CME-UNICAMP) que está sob a coordenação das professoras doutoras Maria do Carmo Martins e Heloísa Helena Pimenta Rocha e foi o órgão responsável pela organização dos acervos das seguintes escolas: Colégio Progresso Campineiro e Grupo Escolar Orosimbo Maia. Disponível em: $<$ http://www. fe.unicamp.br/servicos/centro_memoria/index.htm>.

5 VIÑAO-FRAGO, Antonio. Historia de la educación e historia cultural. Revista Brasileira de Educação, São Paulo, n. 0, p. 63-82, set./dez. 1995.

${ }^{6}$ No caso dos estudos sobre o patrimônio científico é possível detectar que instrumentos científicos podem ter funções diferenciadas em ambientes de ensino. Eles podem passar de ferramentas de investigação a ferramentas de ensino quando vai se perdendo a sua função de uso nos laboratórios. Deve-se levar em conta que, para o ensino, instrumentos científicos são reposicionados em versões para o ensino sendo, muitas vezes, simplificados, reduzidos em escala, petrificam como prática de ensino por meio de simulação de experimentos, são tornados objetos icônicos, como marcos históricos de experiências tornadas históricas e famosas. Cf. HEERING, Peter. Tools for investigations, tools for instruction: potential transformations of instruments in the tranfer from research to teaching. In: HEERING, Peter; WITTJE, Roland. Learning by Doing. Sttutgart: Franz Steiner Verlag, 2001. p. 15-30.

7 MOGARRO, op. cit., p. 78.

8 SOUZA, Rosa Fátima. História da Cultura Material Escolar: um balanço inicial. In: BENCOSTTA, Marcus Levy. Culturas escolares, saberes e práticas educativas. Itinerários Históricos. São Paulo: Cortez Editora, 2007. p. 163-192.

9 ESCOLANO BENITO, Agustín. Materialidades, educación patrimonial y ciudadanía. In: LÓPEZ-OCÓN, Leoncio; ARAGÒN, Santiago; PEDRAZUELA, Mario. Aulas con memoria. Ciencia, educación y patrimonio en los institutos históricos de Madrid (1837-1936). Madrid: CEIMES/Doce Calles/Comunidad de Madrid, 2012. p. 37-48.

${ }^{10}$ Soma-se a este número, mais 142 peças provenientes da coleção de instrumentos científicos do Colégio Marista de Santos que foi desativado em 2009. Essas peças aguardam restauração.

${ }^{11}$ PETRY, Marilia Gabriela. Da recolha à exposição: a constituição de museus escolares em escolas públicas primárias de Santa Catarina (Brasil 1911-1952). Dissertação (Mestrado em Educação), Universidade do Estado de Santa Catarina (UDESC), Florianópolis, 2013.

${ }^{12}$ CHERVEL A.; COMPÈRE, M. M. Les humanités dans l'histoire de l'enseignement français. Histoire de l'Éducation, Service d'histoire de l'éducation, Institute National de Recherche Pédagogique (INRP), p. 6, 1997.

${ }^{13}$ Para o ensino de aritmética, do sistema métrico decimal e da geometria: cartas de Parker, compassos, contadores mecânicos, quadro de geometria, tabuinhas, contador de mão e de pé, caixa de formas geométricas, cadernos de aritética. Para o ensino de linguagem: coleção de abecedários e de cartões parietais para leitura, ardósias, cartas de alfabeto, cadernos de caligrafia. Para o ensino de geografia e história: globo terrestre, tabuleiros de areia, quadros de história do Brasil, mapas. Cf. SOUZA, Rosa Fátima. Templos de Civilização: a implantação da escola primária graduada no estado de São Paulo (1890-1910). São Paulo: Editora da Unesp, 1998. p. 168.

${ }^{14}$ SOUZA, 2007, op. cit., p. 175-176.

${ }^{15}$ POGGIANI, Ana Maria Lourenço. Os Museus Escolares na primeira metade do século XX: Sua importância na educação brasileira. Dissertação (Mestrado em Educação), Universidade Católica de Santos, Santos - SP, p. 20 e 497. 
${ }^{16}$ Sobre a ampliação dos conhecimentos a respeito dos Museus Escolas no estado de São Paulo está sendo desenvolvida, pela pesquisadora Camila Marchi, a dissertação de mestrado intitulada "As práticas de ensino com os museus escolares no estado de São Paulo" sob orientação da profa. dra. Katya Braghini no PEPG em Educação: História, Política, Sociedade (EHPS/PUCSP), financiada pela Capes.

${ }^{17}$ GONDRA, José Gonçalves. O veículo de divulgação da Pedagogia oficial da República: a Revista Pedagógica. Revista Brasileira de estudos Pedagógicos, Brasília, v.78, n.188/189/190, p. 374-395, jan./dez. 1997. Segundo o autor já existiam museus pedagógicos em Londres (1851), Canadá(1756), Petersburgo(1864), Washington (1871), Roma (1875), Amsterdã (1876), Tóquio (1877), Paris (1879), Berna (1879), Bruxelas (1880), Lisboa (1882), Rio de Janeiro (1883) e Madri (1884).

${ }^{18}$ LOPES, Maria Margarete. O Brasil descobre a pesquisa cientifica: Os museus e as ciências naturais no século XIX. São Paulo: Hucitec, 1995. p. 323 e 375.

${ }^{19}$ ALVES, Ana Maria de Alencar. O Ipiranga Apropriado. Ciência Política e poder. O Museu Paulista (1893-1922). São Paulo: Humanitas, 2001. p. 75.

${ }^{20}$ Museu Paulista da Universidade de São Paulo: APMP - FMP (p. 209) D 116.1/ APMP - FMP (p. 209) D1171/ APMP-FMP Relatórios de atividades 1903-1915.

${ }^{21}$ MONOD, Émile. L'Exposition Universelle de 1889: grand ouvrage illustré, historique, encyclopédique, descriptif. Paris: E. Dentu, 1990. v. 4. Publié sous le patronage de M. le Ministre du Commerce, de l'Industrie et des Colonies, Commissaire Général de l'Exposition, p. 285 .

22 FRANCO, J. Catálogo da Biblioteca do Museu Escolar Nacional. Rio de Janeiro: Typ. de G. Leuzinger e Filho, 1885. p. 1-318.

${ }^{23}$ O Seminário Episcopal de São Paulo foi aberto em 9 de novembro de 1856 para a formação sacerdotal na cidade. Dois anos mais tarde, dada a pequena quantidade de escolas secundárias na cidade de São Paulo, foi aberto o Seminário Menor dedicado ao ensino secundário em caráter de internato, na intenção de formação de uma elite, masculina e civilizada. Para administrar o seminário, por ordem do Papa Pio IX, foram recrutados os freis Capuchinhos da Província da Alta Sabóia na França. Aderiram à ideia de dirigir uma escola em São Paulo os seguintes religiosos: frei Affonso Rumilly, Conselheiro da Ordem, acompanhado pelos freis Eugênio e Generoso, frei Firmino Centelhas, da Espanha, e o frei Germano d'Annecy.

${ }^{24}$ Também conhecido como relógio do sol.

${ }^{25}$ SANTOS, Paulo Marques dos. Instituto Agronômico e Geofísico da USP. Memória sobre a sua formação e evolução. São Paulo: Editora da USP, 2003. p. 22-23.

${ }^{26} \mathrm{Na}$ reunião de professores de 7 de abril de 1888, o então reitor do Seminário, o Monsenhor de Pindamonhangaba, João Alves Guimarães leu o conteúdo de uma carta de Annecy. Ata de reunião de professores do Seminário Menor. Arquivo da Cúria Metropolitana de São Paulo. Livro 03 59.01.003.

${ }^{27}$ Procedimentos enviados ao Ministério da Educação e Saúde (até década de 1940) que visava garantir que as provas aplicadas pelo colégio tivessem a mesma validade daquelas elaboradas pelo Colégio Pedro II (RJ), instituição modelar do ensino secundário, e que garantiam acesso ao nível superior. As informações que constam nesse documento permitem traçar um retrato bastante completo, pois continham uma descrição pormenorizada de toda a estrutura física (e de recursos) disponível para o desenvolvimento das aulas. No caso do Arquidiocesano existem dois desses processos, um para a antiga sede na Luz e outro para a "nova" na Vila Mariana. 
${ }^{28}$ Arquivo Nacional - Série Educação IE4 - 134 3791/311.

${ }^{29} \mathrm{O}$ documento da primeira equiparação do Colégio Arquidiocesano de São Paulo está depositado no Arquivo Nacional, na cidade do Rio de Janeiro. Arquivo Nacional - Série Educação IE4 - 134, 3791/311.

${ }^{30}$ Pelo regulamento $n^{\circ} 2857$ de 30 de março de 1898 do Gymnasio Nacional percebe-se que o curso de Physica e Chimica compunham a $5^{\mathrm{a}}$ cadeira, no quinto ano, a $6^{\mathrm{a}}$ cadeira no sexto ano, e a $6^{\text {a }}$ cadeira do sétimo ano, mas eram dadas por lições, separadamente. História Natural e as suas ramificações - Botânica, Zoologia, Geologia, Mineralogia - também acompanham esse currículo em que era necessária a aquisição de instrumentos científicos. Neste mesmo ano, percebe-se a existência do sub-ítem de Biologia no curso de História Natural que desaparece do currículo em 1912 e retorna na Portaria Ministerial no 244 de 25/03/1946. Cf. VECHIA, Ariclê; LORENZ, Karl Michael. Programas de Ensino da Escola Secundaria Brasileira. Curitiba: Editora do Autor, 1998. p.162-185 e p. 386.

${ }^{31} \mathrm{BOCCHI}$, Luna Abrano. A configuração de novos locais e práticas pedagógicas na escola: O museu escolar, os laboratórios e gabinetes de ensino do Colégio Marista Arquidiocesano de São Paulo (1908-1940). Dissertação (Mestrado em Educação), Pontifícia Universidade Católica de São Paulo, São Paulo, 2013.

${ }^{32}$ Livro de ocorrências Diárias. Memorial do Colégio Marista Arquidiocesano de São Paulo, 1935 , p. 47.

${ }_{33}$ Província de S. Paulo, 20 fev.1886, p. 2; O Estado de S. Paulo (OESP) 14 ago. 1901, p. 8; OESP 03 set. 1918, p. 6; OESP 11 jan. 1913.

${ }^{34}$ GRANATO, Marcus. Instrumentos de precisão: fonte para a história e estratégias para a permanência. Revista da Sociedade Brasileira de História das Ciências, v. 2, n. 2, p. 140, jul./ dez. 2004.

${ }^{35}$ Para maiores conhecimentos sobre o assunto, ver GRANATO, Marcus. Conservação e restauração de instrumentos científicos históricos. MAST Colloquia, Rio de Janeiro, v. 9, p. 121-144, 2007.

${ }^{36}$ GRANATO, Marcus. Reflexões sobre o Patrimônio Cultural da Ciência e Tecnologia na Atualidade. Revista Memória em Rede, Pelotas, v. 2, n. 4, dez./mar., p. 85-104, 2010-2011.

${ }^{37}$ Esta expressão, que seria atualmente considerada incorreta, é utilizada pelo autor para designar uma matéria ignorada.

${ }^{38}$ GRANATO, 2010-2011, op. cit., p. 85.

${ }^{39}$ SOUZA, 2007, op. cit., p.176.

\section{Artigo recebido em abril de 2014. Aceito em agosto de 2014.}

